\title{
Creep-Fatigue Interaction in Power Plant Steels
}

\author{
Stuart Holdsworth \\ EMPA Swiss Federal Laboratories for \\ Materials Testing \& Research
}

\begin{abstract}
The consideration of a steel's resistance to creep-fatigue crack initiation and development is an important part of the integrity assessment of high temperature power plant components. Defect-free or defect assessment procedures may be employed depending on the product form from which the component is manufactured, and the criteria adopted for design, inspection-management and remaining-life evaluations. Such assessment procedures require a comprehensive knowledge of the creep-fatigue properties of the component materials, and these are reviewed.
\end{abstract}

Keywords: Creep-fatigue, assessment, steels

\section{Notation}

a Crack length

$A(T, v) \quad$ Material constant in mid- $\Delta K$ fatigue crack growth power laws dependent on metallurgical condition, temperature, environment and frequency (hold time)

$b \quad$ Crack size exponent in short-crack creep-fatigue crack growth rate (Eqns. 9,10)

$B^{\prime} \quad$ Constant in short-crack creep-fatigue crack growth rate (Eqns. 9,10)

$C^{*} \quad$ Parameter characterising stress and strain rate fields at tip of crack in material due to creep

$(\mathrm{d} a / \mathrm{d} N)_{\mathrm{C}} \quad$ Creep crack growth per cycle

$(\mathrm{d} a / \mathrm{d} N)_{\mathrm{F}} \quad$ Fatigue crack growth per cycle

$(d \mathrm{a} / d \mathrm{~N})_{\mathrm{CF}} \quad$ Creep-fatigue crack growth per cycle

$\mathrm{d} a / \mathrm{d} t \quad$ Crack growth per unit time

$D_{\mathrm{C}}, D_{\mathrm{F}} \quad$ Creep damage fraction, fatigue damage fraction

$D_{\mathrm{C}}^{\prime}, D_{\mathrm{F}}^{\prime} \quad$ Damage fraction co-ordinates at point of intersection in bi-linear damage locus

$D\left(s_{\mathrm{L}}\right) \quad$ Constant in creep crack growth law (Eqn. 8), dependent on material and temperature through dependence on creep rupture ductility

$i \quad$ Type of creep-fatigue cycle

$J, \Delta J \quad$ Parameter characterising stress and strain fields at tip of crack in material deforming plastically, cyclic $J$

$K, \Delta K \quad$ Stress intensity factor, cyclic stress intensity factor

$K_{\mathrm{c}} \quad$ Critical stress intensity factor for unstable fracture

$\Delta K_{\text {eff, }} \quad$ Part of $\Delta K$ responsible for crack opening in transients involving a compressive component of loading [19]

$\Delta K_{\text {eq }} \quad$ Equivalent cyclic stress intensity factor [19]

$K_{\text {max }}, K_{\text {mean }}$ Maximum stress intensity factor, mean stress intensity factor

$\Delta K_{\mathrm{o}} \quad$ Fatigue crack growth threshold stress intensity factor

LCF Low cycle fatigue

$m \quad$ Exponent in mid- $\Delta K$ fatigue crack growth power law equations

$N \quad$ Number of cycles

$n_{x, i} \quad$ Number of creep-fatigue cycles of type $i$, for crack initiation criterion, $x$

$N_{x}(\Delta \varepsilon) \quad$ Fatigue endurance to crack initiation, criterion $x$, for a given strain range

$q \quad$ Cyclic strain exponent in short-crack creep-fatigue crack growth rate (Eqns. 9,10)

$r_{\mathrm{p}} \quad$ Size of cyclic plastic zone

$R_{\mathrm{m}}, R_{\mathrm{r}} \quad$ Tensile strength, creep-rupture strength

$t, t_{\mathrm{h}}, t_{\mathrm{r}}(\sigma) \quad$ Time, hold (or steady running) time, time to creep-rupture as a function of stress

$T \quad$ Temperature

$x \quad$ Crack initiation criterion 
$Z \quad$ Elastic follow-up factor [9], i.e. the ratio of the elastic strain recovered during the hold time to the total creep strain accumulated during the hold time

$\varepsilon, \Delta \varepsilon \quad$ Strain, strain range

$\varepsilon_{\mathrm{C}}, \varepsilon_{\mathrm{C}} \quad$ Creep strain, creep strain rate

$\varepsilon_{\mathrm{r}} \quad$ Creep-rupture ductility

$\gamma \quad$ Exponent in creep crack growth law (Eqn. 8)

$\sigma, \sigma_{\mathrm{P}}, \sigma_{\mathrm{S}} \quad$ Stress, primary (directly applied) stress, secondary (self equilibrating) stress

$\sigma_{\text {ref }} \quad$ Reference stress [9]

$v \quad$ Frequency $(\mathrm{d} N / \mathrm{d} t)$

(a) Fatigue dominated

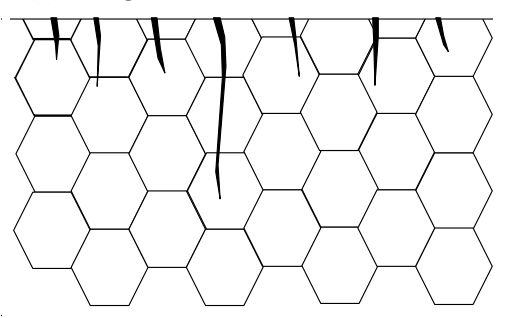

(c) Creep-fatigue interaction

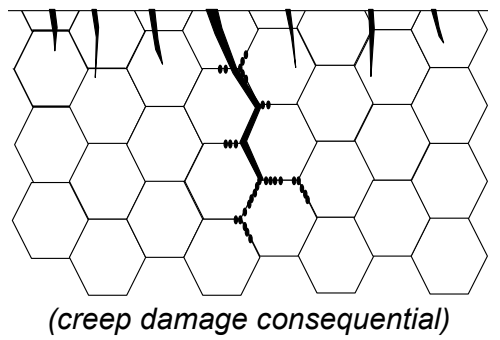

(b) Creep dominated

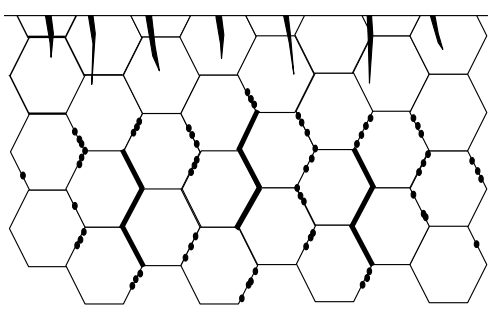

(d) Creep-fatigue interaction

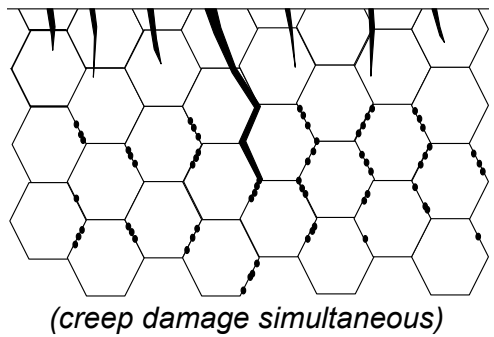

Fig. 1 Creep-fatigue failure mechanisms: (a) fatigue dominated, (b) creep dominated, (c) creepfatigue interaction (due to consequential creep damage accumulation), and (d) creep-fatigue interaction (due to simultaneous creep damage accumulation)

\section{Introduction}

Critical locations in high temperature power plant components may be subject to the combined accumulation of cyclic damage arising from strain transients generated during start-up and shut-down, and creep damage resulting from primary (directly applied) and secondary (self equilibrating) stresses during operation. Traditionally, the risk of creep-fatigue cracking at such locations has been assessed using the results from isothermal tests conducted at (or close to) the peak operating temperature, e.g. $[1,2]$.

The development of creep-fatigue damage in most power plant steels depends on temperature, strain range, strain rate, hold time, and the creep strength and ductility of the material [3-5]. In the absence of a significant hold time (and/or at relatively high strain rates), crack initiation and growth is fatigue dominated, even at high application temperatures (Fig. 1a). With increasing hold time (and/or decreasing strain rate) at high temperature, the creep damage condition within the structure becomes increasingly influential, to the limit beyond which crack development becomes fully creep dominated (Fig. 1b). At intermediate hold times and strain rates, fatigue cracking interacts with creep damage developing consequentially or simultaneously resulting in accelerated crack growth (Fig. 1c and d). The extent of any interaction increases with decreasing creep ductility [4].

The creep-fatigue resistance of power plant steels may be characterised in terms of different parameters depending on whether the engineering component evaluation interest is defect-free or defect assessment. Defect-free or defect assessment procedures may be employed depending on the 
product form from which the component is manufactured, and the criteria adopted for design, inspection-management or remaining-life evaluations. The creep-fatigue properties required for both types of assessment procedure are reviewed in the following paper.

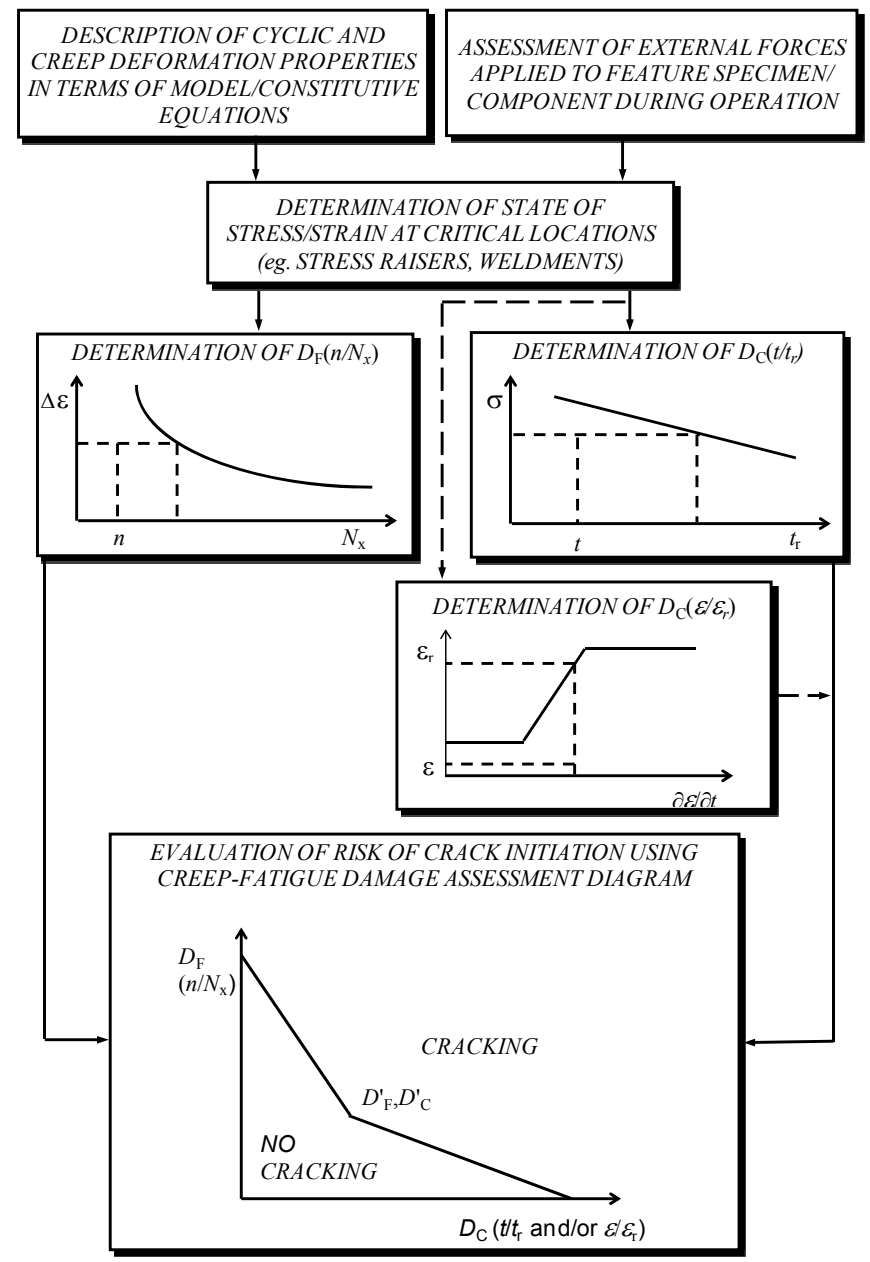

Fig. 2 Common steps in creep-fatigue assessment procedures

\section{Defect-Free Assessment}

\subsection{Overview}

A simplified representation of the common steps in a number of creep-fatigue defect-free assessment procedures (e.g. [6-9]) is shown in Fig. 2. The component is fully assessed in terms of the external thermo-mechanical boundary conditions imposed during the operating lifetime, and these are used in conjunction with material constitutive equations to define the distribution of stress and strain throughout the structure. Having established the stress/strain state history at critical locations, cyclic and creep damage fractions $\left(D_{\mathrm{F}}\right.$ and $\left.D_{\mathrm{C}}\right)$ are determined by reference to the appropriate material endurance property data. The $D_{\mathrm{F}}$ and $D_{\mathrm{C}}$ fractions are finally compared with the crack initiation locus in a creep-fatigue damage assessment diagram and the risk of failure evaluated.

\subsection{Determination of Local Stress/Strain State}

Analysis options to determine the state of stress and strain at critical locations vary from simplifiedelastic, for structures which can be shown to operate in shakedown (e.g. [9]), to evolutionary fullinelastic, requiring a detailed description of deformation as a function of temperature, strain rate and any metallurgical changes leading to cyclic hardening or softening relative to monotonic behaviour (e.g. Fig. 3). At one analytical extreme, steady-state cyclic and creep deformation are assumed, with time independent plasticity and creep behaviour being clearly distinguished. However, alternative 
approaches range in increasing complexity to the adoption of fully unified state variable constitutive material models (e.g. [10]).

(a)
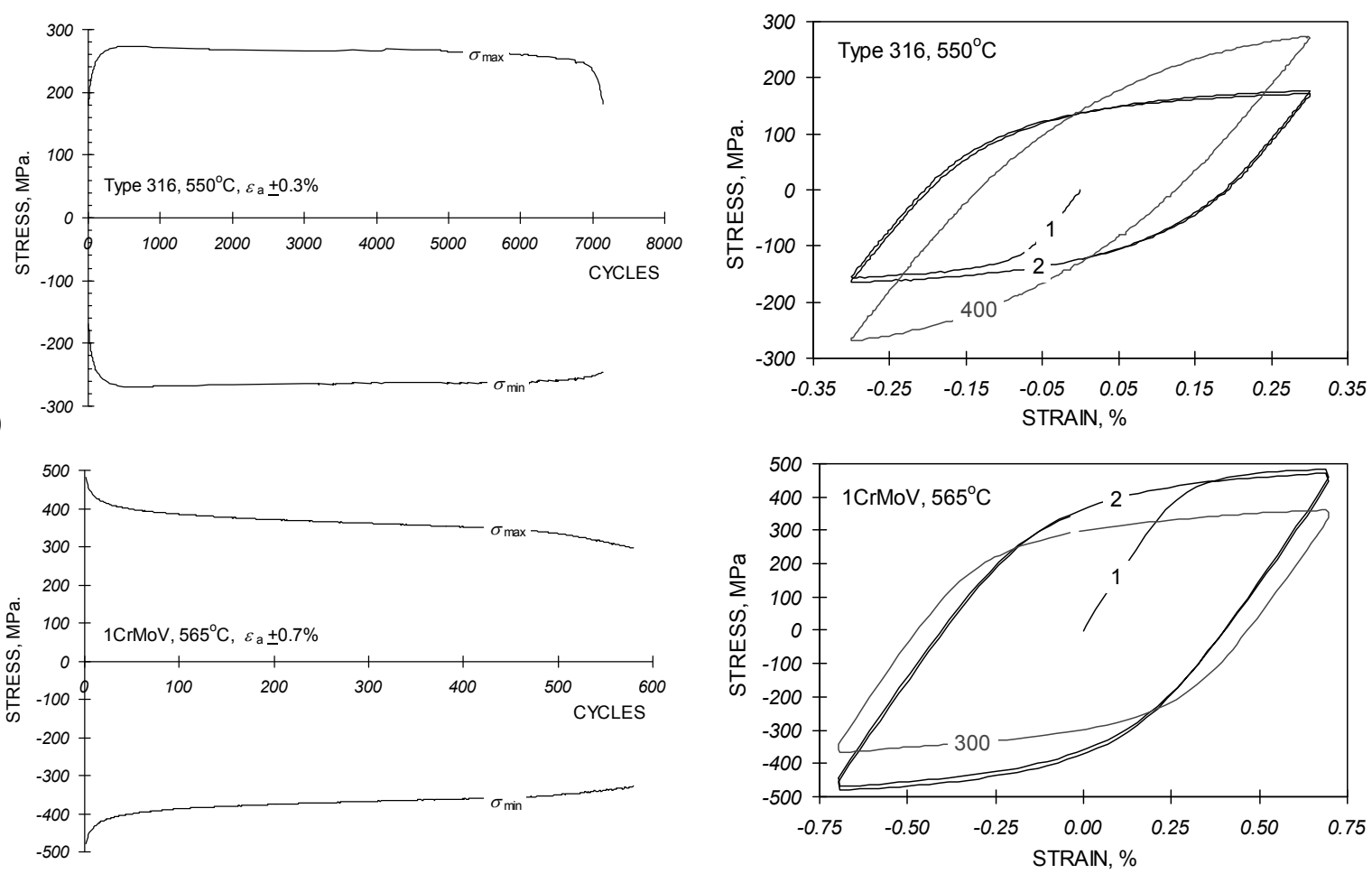

Fig. 3 Examples of (a) cyclic hardening and (b) cyclic softening behaviour in high temperature strain-controlled LCF tests in two power plant steels (grey loops are mid-life $\varepsilon(\sigma)$ loops)

Important material property information for the determination of local stress and strain state are cyclic stress-strain deformation characteristics derived from low cycle fatigue (LCF) endurance or multiple step tests, and creep strain data determined from constant load or stress relaxation tests.

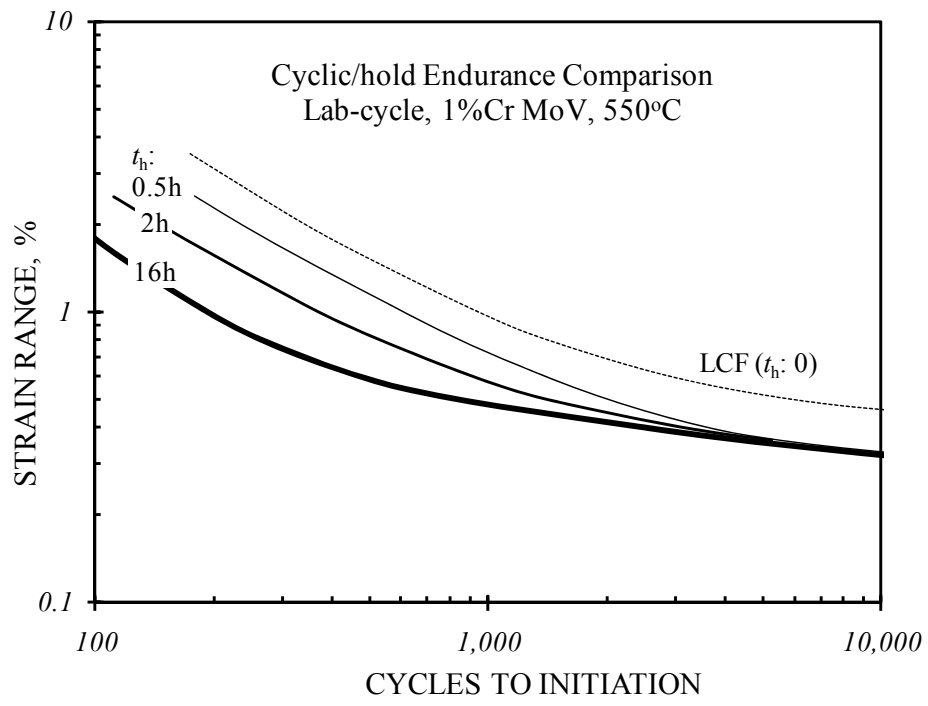

Fig. 4 Influence of hold time on cyclic/hold $N_{\mathrm{x}}\left(\Delta \varepsilon, t_{\mathrm{h}}\right)$ crack initiation endurance for $1 \% \mathrm{CrMoV}$ at $550^{\circ} \mathrm{C}[3]$ 


\subsection{Calculation of Creep-Fatigue Damage}

Creep-fatigue assessment procedures are broadly differentiated by the way the components of fatigue and creep damage are determined. As a generality, they fall into two main categories, depending on how the creep damage due to secondary (self equilibrating) loading is calculated, i.e. by time-fraction or strain-fraction analysis methods. Time-fraction methods are currently the most widely used to determine the creep-fatigue damage accumulated (e.g. [6-8]). In any case, a time fraction approach is invariably used to determine the creep usage arising from directly applied loading.

In time-fraction approaches, creep usage is determined as a function of time, i.e.

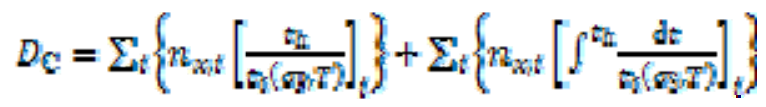

The two terms on the right hand side of Eqn. 1 respectively cover the damage accumulated due to primary and secondary loading. The stress rupture times $t_{\mathrm{r}}\left(\sigma_{\mathrm{P}}, T\right)$ and $t_{\mathrm{r}}\left(\sigma_{\mathrm{S}}, T\right)$ are determined using creep rupture data for the appropriate material and temperature.

The best known approach for the determination of creep damage in terms of strain-fraction (or ductility exhaustion) is that adopted in the R5 procedure [9], i.e.

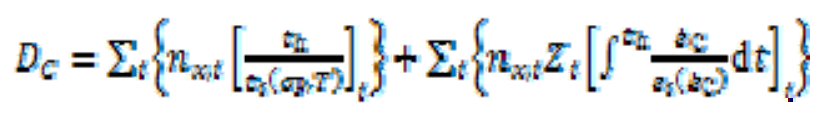

where $Z_{i}$ is the elastic follow-up factor for the $i$ th cycle type, and $g_{\mathrm{r}}\left(d_{\text {) }}\right.$ characteristics are determined from the results of creep-rupture tests. The determination of creep damage fraction as a function of ductility exhaustion is a developing area, and it has already been demonstrated that a stress modified version of the denominator in the second term of Eqn. 2 can provide a more effective indication of the state of ductility exhaustion (e.g. [11]).

Fatigue damage fraction is typically determined from a model representation of smooth specimen $N_{x}(\Delta \varepsilon)$ LCF crack initiation endurance data, e.g. [12], and the expression:

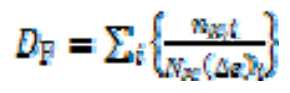

Some analysts account for creep damage due to secondary loading as part of the fatigue damage fraction calculation by using a $N_{x}\left(\Delta \varepsilon, t_{\mathrm{h}}\right)$ endurance model based on observations from cyclic/hold tests in Eqn. 3, e.g. [1,2]. In such circumstances, creep damage fraction is estimated using only the first term in Eqn. 1 (or Eqn. 2). An example of the effect of hold time on cyclic/hold crack initiation endurance is shown in Fig. 4.

\subsection{Damage Summation}

The ways in which creep and fatigue damage may be summed are conveniently illustrated with reference to possible crack initiation locus options in a creep-fatigue damage summation diagram (Fig. 2). Bi-linear damage loci, as used in $[6,8]$, may be modelled using:

$$
\begin{array}{ll}
D_{\mathrm{F}}=1-D_{\mathrm{C}}\left(1-D_{\mathrm{F}}\right) / D_{\mathrm{C}} & \text { for } D_{\mathrm{C}} D_{\mathrm{C}} \\
\left.D_{\mathrm{F}}=\left(1-D_{\mathrm{C}}\right) D_{\mathrm{F}} / 1-D_{\mathrm{C}}\right) & \text { for } D_{\mathrm{C}}>D_{\mathrm{C}}
\end{array}
$$

where $D_{\mathrm{F}}^{\prime}, D_{\mathrm{C}}^{\prime}$ define the intersection co-ordinates [13]. For linear damage accumulation, as in [7,9], $D_{\mathrm{F}}^{\prime}, D_{\mathrm{C}}^{\prime}=0.5$. Alternatives are the L-shaped locus adopted in [14] and more recently the quadratic locus which is said to represent the theoretical lower bound [15]. Apart from the theoretically based quadratic representation, other damage summation options are determined on the basis of experimental observations from cyclic/hold or service-cycle thermo-mechanical fatigue tests, e.g. [17].

\section{Cyclic/Hold Test Endurances}

The thermal cycles experienced by power plant components are invariably complex and engineering assessments are based on idealised cycle shapes. The cyclic/hold endurance data determined for 
material characterisation purposes and to provide input parameters for engineering assessment have traditionally been acquired from isothermal tests involving one of two laboratory cycle types, e.g. Fig. 5. Both strain controlled cycles involve a transient into compression followed by a through zero strain ramp into tension with a hold period at peak strain in tension. The two cycles differ in that there is a hold time at peak strain in compression in the case of the Dlab-cycle but not in the case of the Labcycle. Data from such experimental tests are ideal for the verification of damage summation diagrams, providing the associated damage mechanism is relevant to the practical circumstances under evaluation.

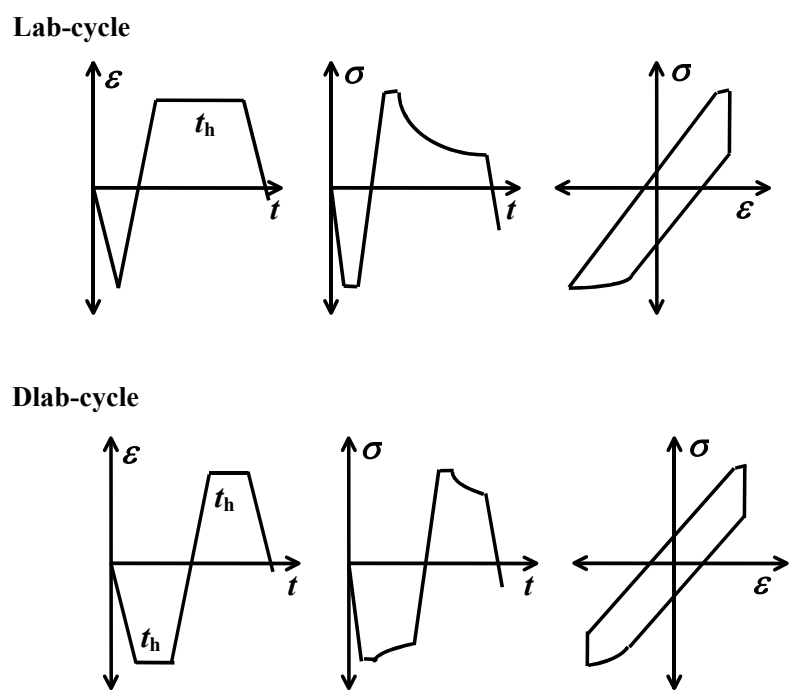

Fig. 5 Common cycle types used for cyclic/hold creep-fatigue property determination

In the 1960s to 1980 s, it was not uncommon for hold periods of cyclic/hold endurance tests to last for several hours, e.g. Fig. 4 [3]. More recently there have apparently not been the resources for such long duration tests, and materials have been characterised and damage summation diagrams benchmarked with the results from cyclic/hold tests with much shorter hold times. For situations, where there is still a requirement for longer hold time cyclic/hold $N_{x}\left(\Delta \varepsilon, t_{\mathrm{h}}\right)$ endurance data, it is possible to generate the information using a reverse analysis route based on the flow diagram given in Fig. 2. The concept is examined in [17].

Prior to the $1990 \mathrm{~s}$, steam inlet temperatures for large turbo-generators rarely exceeded $\sim 565^{\circ} \mathrm{C}$. During this period (and to the present time), critical steam turbine components in operational duty to this temperature were typically manufactured from $\mathrm{CrMoV}$ steels. For this application, optimised steels in this alloy class had an excellent service record which was underpinned by a significant quantity of high temperature LCF and cyclic/hold creep-fatigue data, e.g. $[3,13,16]$. The creep-fatigue endurance properties for $1 \% \mathrm{CrMoV}$ provided the reference data against which the properties of a range of advanced $9-11 \% \mathrm{Cr}$ steels were compared in [17]. This review of the available cyclic/hold endurance data for a number of $9-11 \% \mathrm{Cr}$ steels demonstrated that the creep-fatigue resistance of the new advanced martensitic alloys was significantly superior to that for the $1 \% \mathrm{CrMoV}$ turbine steels at $550^{\circ} \mathrm{C}$. Moreover, it showed that cyclic/hold endurances for the new advanced steels at $600^{\circ} \mathrm{C}$ were at least as good as those for $1 \% \mathrm{CrMoV}$ at $550^{\circ} \mathrm{C}$ (Fig. 6).

The superior creep-fatigue endurances of the new $9-11 \% \mathrm{Cr}$ steels relative to conventional $1 \% \mathrm{CrMoV}$ turbine steels were matched by a high temperature resistance to creep-rupture and lower expansion coefficients, thus making the new alloys ideally suited for high performance, high efficiency steam turbine applications at temperatures at least up to $600^{\circ} \mathrm{C}$ [17].

Published cyclic/hold deformation and endurance data for a wide range of power plant steels are available from a number of sources (e.g. [16,17]). 


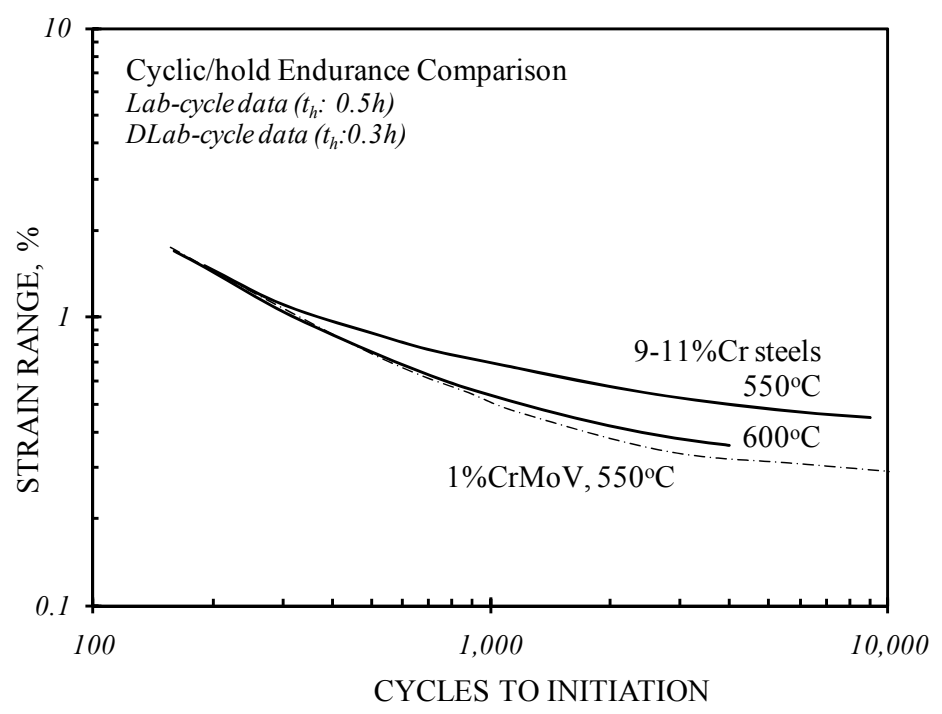

Fig. 6 Comparison of minimum cyclic/hold $N_{\mathrm{x}}\left(\Delta \varepsilon, t_{\mathrm{h}}\right)$ endurance data lines for $1 \% \mathrm{CrMoV}$ at $550^{\circ} \mathrm{C}$, and $9-11 \% \mathrm{Cr}$ steels at 550 and $600^{\circ} \mathrm{C}$ [17]

\section{Defect Assessment}

\subsection{Background}

Cracks established during component manufacture or service may subsequently propagate during high temperature duty as a consequence of the combined effects of cyclic and creep loading. An important consideration in the characterisation of creep-fatigue crack growth rates and the defect assessment of high temperature components is the size of the crack relative to the size of the cyclic plastic zone at the surface. In the following text, long cracks are those whose size exceeds that of $r_{\mathrm{p}}$, and short cracks are those whose size is less than that of $r_{\mathrm{p}}$.

\subsection{Long Crack Growth}

Cyclic crack growth is conventionally considered in terms of three regimes; these being: a low- $\Delta K$ regime close to the fatigue crack growth threshold $\left(\Delta K_{\mathrm{o}}\right)$, a mid- $\Delta K$ regime in which propagation rates are modelled by a power law (e.g. Eqn. 5), and a high- $\Delta K$ regime in which $K_{\max }$ approaches $K_{\mathrm{c}}$ (or $\sigma_{\text {ref }}$ approaches $R_{\mathrm{m}}$ or $R_{\mathrm{r}}$ ).

$$
(\mathrm{d} \alpha / \mathrm{d} N)_{\mathrm{E}}=A(T, v)_{\mathrm{n}}\left(\Delta K^{2}\right)^{\mathrm{m}}
$$

In Eqn. 5, $A(T, v)$ and $m$ are material constants dependent on temperature, environment and frequency (below a limiting value, see below).

At low $\Delta K$ levels close to $\Delta K_{0}$, the magnitude of $\mathrm{d} a / \mathrm{d} N$ is very sensitive to small increases in $\Delta K$ and dependent on the same factors which influence $\Delta K_{0}$, i.e. material, microstructure and yield strength, temperature, environment and $K_{\text {mean. }}$ Propagation rates in the mid- $\Delta K$ regime are less sensitive to microstructure and $K_{\text {mean }}$ effects. In the high- $\Delta K$ regime, $\mathrm{d} a / \mathrm{d} N$ becomes increasingly sensitive to the level of $\Delta K$ and in particular $K_{\max }$ (and/or $\sigma_{\text {ref,max }}$ ) as $K_{\mathrm{c}}$ (and/or plastic-collapse/creep-rupture) is approached [9]. Depending on the deformation and fracture characteristics of the material, crack growth rates can be strongly influenced by size and geometry. In these circumstances, a simple linear elastic fracture mechanics defined $\Delta K$ is not the most effective correlating parameter and alternative energy based cyclic loading parameters such as $\Delta J$ or $\Delta K_{\text {eq }}$ are employed in Eqn. 5 (e.g. [18,19]). In addition to the factors already mentioned, $\mathrm{d} a / \mathrm{d} N$ in the high- $\Delta K$ regime is strongly dependent on microstructure, $K_{\text {mean }}$, temperature, environment and frequency (strain rate).

At lower frequencies, oxidation and creep interaction effects become more influential (e.g. Fig. 7). In load control, below a limiting frequency, crack growth rates may be regarded as being dominated by 
the time dependent component of the damage mechanism (i.e. creep crack growth in Fig. 8). The high temperature behaviour shown in Fig. 8 is typical for many power plant materials in the mid- $\Delta K$ regime in load control [20].

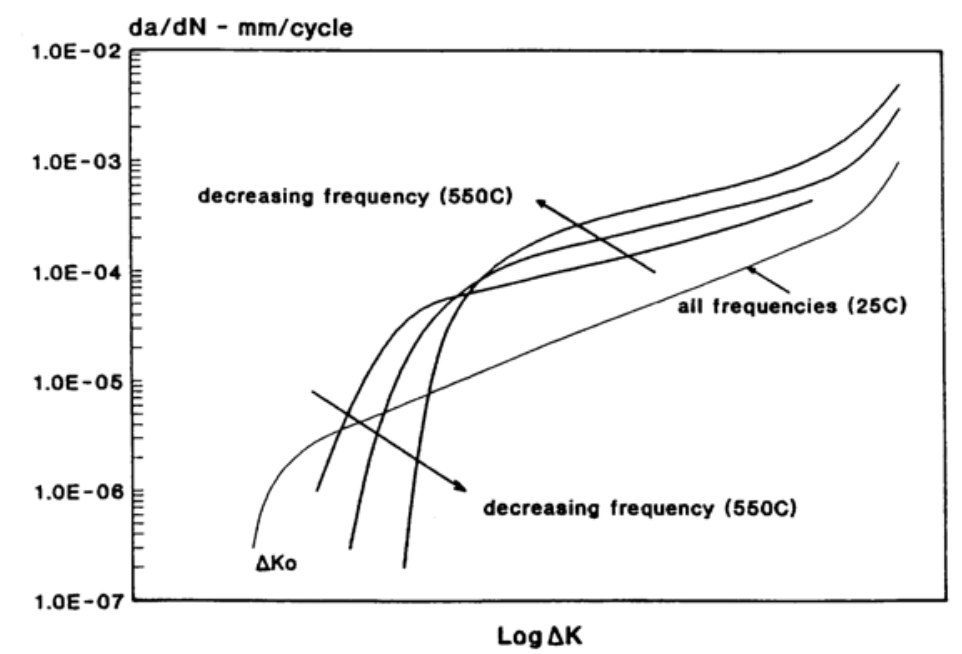

Fig. 7 Effect of frequency on high temperature fatigue crack growth rates in $1 \mathrm{CrMoV}$ steel [22]

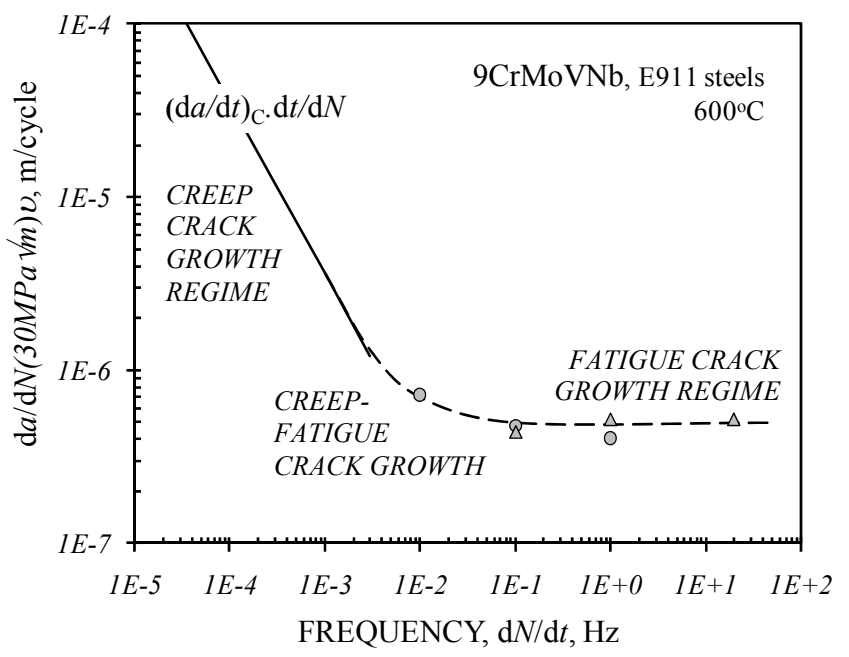

Fig. 8 Effect of frequency on high temperature mid- $\Delta K$ crack growth rates [21]

In contrast, crack growth rates in the low- $\Delta K$ regime can reduce and $\Delta K_{\text {th }}$ values increase with decreasing frequency due to oxide wedging and premature crack closure (Fig. 7).

At high temperatures, the high growth rates associated with the high- $\Delta K$ regime can be generated either as a consequence of relatively high magnitude cyclic loading applied remotely to a long crack (e.g. [19], or (usually at an initial stage of thermal fatigue crack development) as high strain transients applied locally to a small crack contained in the cyclic plastic strain field (e.g. [23], see Sect. 4.3). In the former case, cyclic crack growth rate behaviour is modelled using a modified form of Eqn. 5, e.g.

$$
(d a / d W)_{F}=A\left(T, v, t_{b},\left(\Delta K_{\mathrm{s}}\right)^{\mathrm{m}}\right.
$$

where $\Delta K_{\text {eq }}$ is $\Delta K_{\text {eff }}$ for purely elastic tensile loading. Acknowledgement of the dependence of $A(T, v)$ on hold time in these circumstances reflects the potential dependence of this parameter on associated oxidation as well as creep damage [19]. 


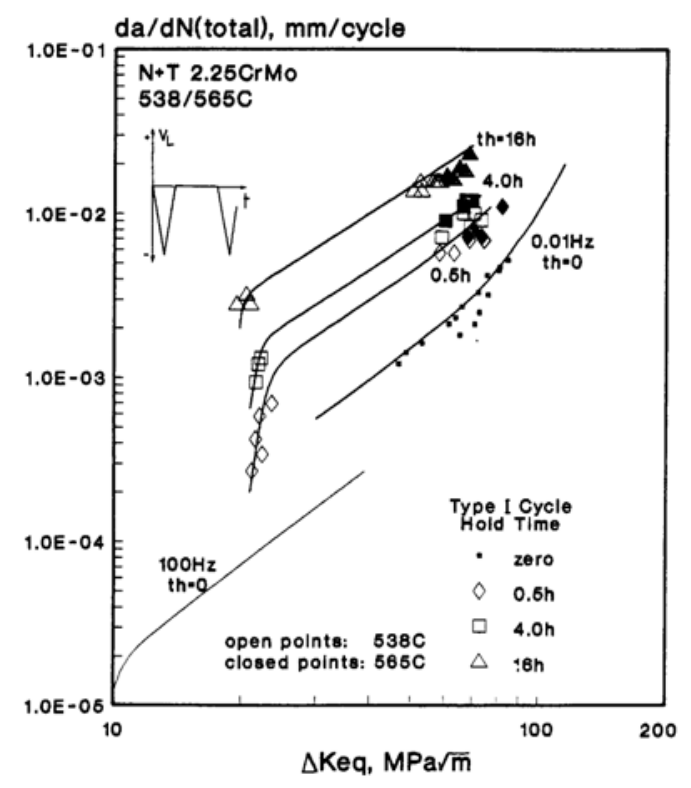

Fig. 9 Long crack cyclic/hold creep-fatigue crack growth test data for $2 \frac{1}{4} 4 \mathrm{CrMo}$ cast turbine steel at $538 / 565^{\circ} \mathrm{C}[19]$

The creep-fatigue crack growth properties required for the defect assessment of components subject to fatigue cycles involving hold (steady operating) periods may be derived from pure fatigue and pure creep crack growth rate data in a construction of the form given in Fig. 8 when the load is directly applied (i.e. load controlled). In such circumstances, the effective frequency may be simply determined from a knowledge of the total cycle time (i.e. transient + hold time). Alternatively, creepfatigue crack growth behaviour is analytically modelled on the basis of fatigue and creep crack growth rate characteristics for the material, i.e.

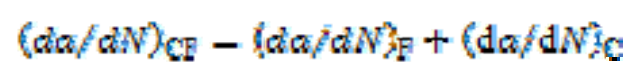

In Eqn. 7, $(\mathrm{d} a / \mathrm{d} N)_{\mathrm{F}}$ is given by Eqn. 6, where $A\left(T, v, t_{\mathrm{h}}\right)$ may be influenced by creep and oxidation damage through its dependence on frequency and hold time [19], and $(\mathrm{d} a / \mathrm{d} N)_{\mathrm{C}}$ is given by Eqn. 8.

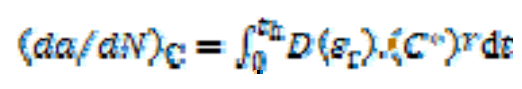

Any enhancement of the total growth rate per cycle due to creep-fatigue-oxidation interaction is covered by $A\left(T, v, t_{\mathrm{h}}\right)$ which may be determined experimentally (e.g. Fig. 9 [19]).

\subsection{Short Crack Growth}

The high strain fatigue crack growth rates associated with small cracks contained in local plastic strain fields (typically $a \leq 5 \mathrm{~mm}$ ) are most effectively modelled as a function of $\Delta \varepsilon$ [23-25] (e.g. Fig. 10):

$$
(\mathrm{d} a / \mathrm{d} M)_{\mathrm{CF}}=\mathrm{B}^{\mathrm{s}}, a^{2} \cdot\left(\Delta g^{\mathrm{q}}\right)
$$

For relatively short cracks contained in high cyclic plastic strain fields, $(\mathrm{d} a / \mathrm{d} N)_{\mathrm{CF}}$ is effectively modelled using a refinement of Eqn. $9[23,24]$, i.e.

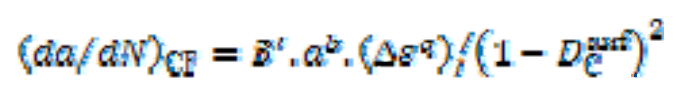

The effect of hold time on high strain fatigue crack growth rate for a $1 \frac{1}{4} \mathrm{CrMoV}$ steel at $550^{\circ} \mathrm{C}$ is shown in Fig. 10. In this example, $D_{\mathrm{C}}$ is modelled as a function of hold time, i.e. Eqn. 11, but in a formal assessment would be determined using Eqn. 1 or Eqn. 2

$$
D_{\mathrm{g}}=\sigma_{1} \cdot\left(\ln \left(\alpha_{2} t_{2}+1\right)\right)
$$

where $\alpha_{1}$ and $\alpha_{2}$ are empirical constants. 


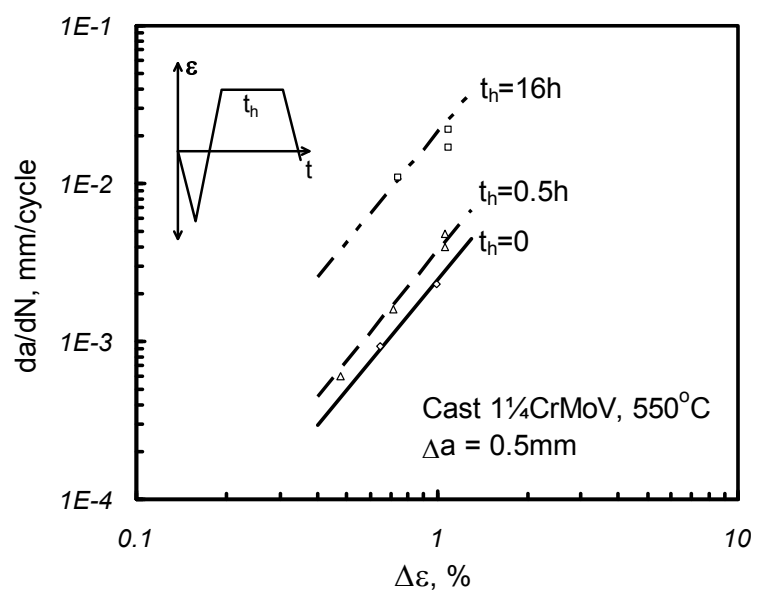

Fig. 10 Comparison of crack growth rates after $0.5 \mathrm{~mm}$ crack extension from notch root in large SENB

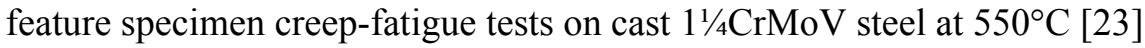

It is evident that the material property data required for the defect assessment of high temperature components subject to creep-fatigue loading can be strongly dependent on the specific operating conditions relating to the practical application under consideration. This means that the rigorous creep-fatigue defect assessment of a component can require a significant investment in the determination of appropriate material property data. It is therefore important to demonstrate that both creep and fatigue loading are significant at critical features.

\subsection{Assessment Methods}

Creep-fatigue crack growth assessments are usually only considered to be necessary when both creep and fatigue deformation and damage accumulation are shown to be significant [9]. When both creep and cyclic loading are shown to be significant, the extent of creep-fatigue interaction should be determined.

As a generality, the effect of creep damage on fatigue crack growth rates has little additional influence on the total crack growth per cycle providing the latter includes an explicit calculation of creep crack growth (i.e. Eqn. 7). In such circumstances, there is no creep-fatigue interaction and no requirement to enhance fatigue crack growth rates. It is only necessary to consider a creep-fatigue interaction when the effect of cyclic loading on creep can be shown to be significant despite fatigue crack growth having been estimated to be only a small fraction of the total crack growth per cycle. In such circumstances, the constants in Eqn. 6 should be determined from tests with hold times relevant to the service application being assessed (e.g. Fig. 9). This type of interaction typically occurs when creep damage is generated as a consequence of the growing fatigue crack (e.g. Fig. 1c). In cases where cracks propagate by fatigue through material heavily damaged by prior creep (or simultaneously generated creep, e.g. Fig. 1d), propagation rates are likely to be enhanced. In these circumstances, it is usually only possible to enhance fatigue crack growth parameters by appropriate experimentally determined factors.

The type of crack growth data required for high temperature defect assessment depends on the size of the defect relative to the cyclic plastic zone at the surface of the component. For cracks larger than the cyclic plastic zone (Fig. 11a), a Paris type law modified for crack closure is used (e.g. Eqn. 6 in conjunction with Eqn. 7). In the R5 procedure [9], this approach is referred to as Method-I. For small defects embedded in the cyclic plastic zone (Fig. 11b), a strain based method for the calculation of crack growth is adopted. This approach is referred to as Method-II [9]. 


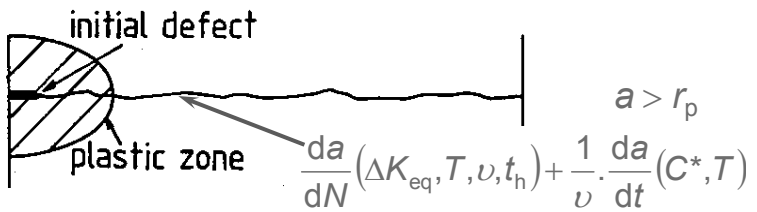

(a)

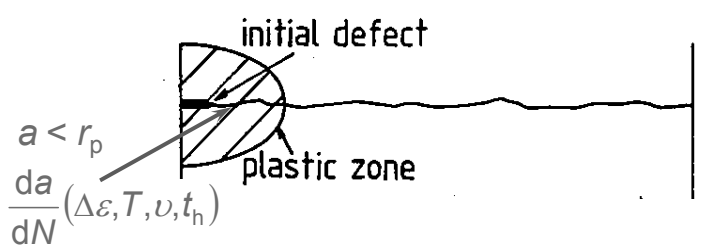

Method-I (b) Method-II

Fig. 11 Assessment methods for cracks extending either (a) beyond $\left(a>r_{\mathrm{p}}\right)$ or (b) within $\left(a<r_{\mathrm{p}}\right)$ cyclic plastic zones at the component surface when creep is significant

In Method-I, fatigue crack growth rate $(\mathrm{d} a / \mathrm{d} N)_{\mathrm{F}}$ is given by Eqn. 6 with the constants modified for hold time effects if creep-fatigue interactions are shown to be significant. If fatigue crack growth is shown to be insignificant, the high temperature defect assessment procedure focuses on the use of Eqn. 7 without $(\mathrm{d} a / \mathrm{d} N)_{\mathrm{F}}[9]$.

Method-II is applied for cracks growing inside the cyclic plastic zone at the component surface, when creep is significant (Fig. 11b). In this regime, a high strain creep-fatigue crack growth law such as Eqn. 10 is used. $D_{\mathrm{C}}^{\text {aurf }}$ is the total surface creep damage (taking account of stress state if necessary) accumulated in the appropriate time from every cycle, and is:

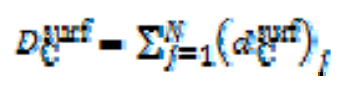

where $d g$ is the creep damage accumulated in the $j$ th cycle and the summation is carried out over the appropriate time. dert is evaluated at the surface of the uncracked component, for example using the approaches represented by Eqn. 1 or Eqn. 2.

\section{Concluding Remarks}

The consideration of a steel's resistance to creep-fatigue crack initiation and development is an important part of the integrity assessment of high temperature power plant components. Defect-free or defect assessment procedures may be employed depending on the product form from which the component is manufactured, and the criteria adopted for design, inspection-management and remaining-life evaluations. The details of these have been examined.

Creep-fatigue defect-free and defect assessment procedures require a significant quantity of material property data to provide calculation input parameters and the necessary information for analysis method benchmark verification. The results from cyclic/hold tests provide a useful contribution to this required knowledge base.

\section{References}

1 Timo DP. Designing turbine components for low-cycle fatigue. In: Proc. Intern. Conf. on Thermal Stresses and Fatigue, Berkeley, UK, 22-26/9/1969, 453-469.

2 Dawson RAT. Monitoring and control of thermal stress and component life expenditure in steam turbines. In: Proc. Intern. Conf. on Modern Power Stations, AIM, Liège, September 1989.

3 Thomas G, Dawson RAT. The effect of dwell period and cycle type on high strain fatigue properties of $1 \mathrm{CrMoV}$ rotor forgings at $500-550^{\circ} \mathrm{C}$. In: Proc. Intern. Conf. on Engineering Aspects of Creep, Sheffield, 1980, Paper C333/80, 167-173.

4 Miller D, Priest RH, Ellison EG. A review of material response and life prediction techniques under creep fatigue loading conditions. High Temp. Mater. \& Processes. 1984;6(3,4):155-194.

5 Bicego V, Fossati C, Ragazonni S. Low cycle fatigue characterisation of a HP-IP steam turbine rotor. In: Soloman HO et al. editors. Low Cycle Fatigue. Philadelphia: ASTM STP 942, 1988:1237-1260. 
6 ASME Boiler and Pressure Vessel Code, Section III, Division 1: Sub-section NH, Class 1 Components in Elevated Temperature Service, ASME, New York, 2001.

7 TRD 301. Annex I - Design: Calculation for Cyclic Loading due to Pulsating Internal Pressure or Combined Changes of Internal Pressure and Temperature, Technical Rules for Steam Boilers. 1978.

8 RCC-MR. Design and Construction Rules for Mechanical Components of FBR Nuclear Islands. AFCEN, Paris, 1985.

9 R5. Assessment Procedures for the High Temperature Response of Structures, Procedure R5. Issue 3, British Energy, Gloucester, 2003.

10 Lemaitre J, Chaboche J-L. Mechanics of Solid Materials. Cambridge Univ. Press. 1990.

11 Spindler MW. The multiaxial and uniaxial creep ductility of type 304 steel as a function of stress and strain rate. Materials at High Temperatures 2004;21(1):47-52.

12 Coffin LF. A study of the effects of cyclic thermal stresses on a ductile metal. Trans ASME (Series A) 1954;76:931-950.

13 Holdsworth SR. Prediction of creep-fatigue behaviour at stress concentrations in $1 \mathrm{CrMoV}$ rotor steel. In: Proc. Conf. on Life Assessment and Life Extension of Engineering Plant, Structures and Components, Churchill College, September 1996, 137-146.

14 Bestwick RDW, Clayton A. Design methodology for creep-fatigue assessment using creep ductility criteria. In: Proc. 5th Intern. Seminar on Inelastic Analysis and Life Prediction in High Temperature Environment, Paris, 1985, 55-60.

15 Skelton RP, Gandy D. Creep-fatigue damage accumulation and interaction diagram based on metallographic interpretation of mechanisms. Materials at High Temperatures 2008;25(1):27-54.

16 Bhongbhibhat S. Dehnungswechselkurven. Forschungsberichte, Universität Stüttgart, Heft 275, 1980.

17 Holdsworth SR. Creep-fatigue of high temperature turbine steels. Materials at High Temperatures 2001;18(4):261-265.

18 Dowling NE. Crack growth during low cycle fatigue. In: Cyclic Stress-Strain and Plastic Deformation Aspects of Fatigue Crack Growth, ASTM STP 637, 1977, 97-121.

19 Holdsworth SR. Factors influencing the high temperature HSF crack growth rates in turbine casting steels. In: Ainsworth RA, Skelton RP, editors. Behaviour of Defects at High Temperatures, ESIS 15, MEP, London, 1993, 327-349.

20 Holdsworth SR. High temperature fatigue crack growth. In: Marriott JB, editor. High Temperature Crack Growth in Steam Turbine Materials, CEC COST Monograph EUR 14678EN, 1994, 129176.

21 Holdsworth SR. Material data requirements for assessing defect integrity at high temperatures. In: Strang A, editor. Materials for High Temperature Power Generation and Process Plant Applications, IOM, 2000, 177-197.

22 Skelton RP, Haigh JR. Fatigue crack growth rates and thresholds in steels under oxidizing conditions. Mat. Sci. Eng. 1978;36:17-25.

23 Holdsworth SR. Creep-fatigue crack growth from a stress concentration. Materials at High Temperatures, 1998;15(2):111-116.

24 Levaillant C, Pineau A. Assessment of high temperature low cycle fatigue life of austenitic stainless steels using intergranular damage as a correlating parameter. In: Low Cycle Fatigue and Life Prediction, ASTM STP 770, Philadelphia: ASTM, 1982, 169-193.

25 Skelton RP. Damage factors during high temperature fatigue crack growth. In: Ainsworth RA, Skelton RP. editors, Behaviour of Defects at High Temperatures, ESIS-15, MEP, London, 1993, 191-218. 